\title{
Preface
}

This book is the consequence of a year-long policy research project in the LBJ School of Public Affairs and the Institute of Latin American Studies (ILAS) at the University of Texas at Austin. Structured in the form of a sustained dialogue, discussion was focused around formal presentations by Brazilian specialists followed by informal meetings between them and advanced students engaged in policy research. The specialists also reviewed and commented on the work under way. The papers selected for publication here represent a continuation of that dialogue; they constitute a cross section of the work presented by seminar participants and papers finalized afterward in the United States and Brazil.

The project received funding from ILAS, including grants from the U.S. Department of Education through its Latin American Language and Area Center Program, and the Lyndon Baines Johnson Foundation. This project benefited from the support and participation of many people. William Glade, the former director of ILAS, Richard Adams, the current director, and Max Sherman, dean of the LBJ School, provided support and encouragement in all phases of the project. The participation of a number of colleagues at the University of Texas at Austin, including Michael Conroy, Fred Ellison, Richard Graham, and David Jackson, and scholars from other institutions, including Werner Baer, Vilmar Faria, Henrique Lewandowski, and Wayne Selcher, greatly enriched our efforts. Christine Payne provided excellent editorial assistance. 
THIS PAGE INTENTIONALLY LEFT BLANK 


\section{The Political Economy of Brazil: \\ Public Policies in an Era of Transition}


THIS PAGE INTENTIONALLY LEFT BLANK 